\title{
Classification of Sialolithiasis by Location of Stones: Retrospective Review of 534 Cases
}

\author{
Jisoo Lee, Juho Han, Sunwook Kim, Hyogeun Choi, and Bumjung Park \\ Department of Otorhinolaryngology-Head and Neck Surgery, Hallym University Sacred Heart Hospital, Hallym University \\ College of Medicine, Anyang, Korea
}

타석증의 발생 위치에 따른 분류: 후향적 차트 리뷰 534예

이지수 · 한주호 · 김선욱 · 최효근 · 박범정

한림대학교 의과대학 한림대학교 성심병원 이비인후-두경부외과학교실

\author{
Received December 12, 2018 \\ Revised April 23, 2019 \\ Accepted May 7, 2019 \\ Address for correspondence \\ Bumjung Park, MD \\ Department of Otorhinolaryngology- \\ Head and Neck Surgery, \\ Hallym University \\ Sacred Heart Hospital, \\ Hallym University \\ College of Medicine, \\ 22 Gwanpyeong-ro 170beon-gil, \\ Dongan-gu, Anyang 14068, Korea \\ Tel $+82-31-380-3842$ \\ Fax $+82-31-386-3860$ \\ E-mail pbj426@hallym.or.kr
}

Background and Objectives To investigate epidemiological features of patients with sialolithiasis and to evaluate the difference in outcomes depending on its location.

Subjects and Method We included in the test 472 patients, or 534 cases, who were admitted to the Hallym University Sacred Heart Hospital between February 2006 and May 2017 with the diagnosis of sialolithiasis. The diagnosis of sialolithiasis was established by CT images; all of the cases were classified by the location of stones (orifice to stone/orifice to hilum: $0-0.25$, type I; $0.25-0.5$, type II; $0.5-0.75$, type III; $0.75-1$, type IV).

Results The average size of stone was $7.2 \pm 4.8 \mathrm{~mm}$ and the mean patient age was $36.1 \pm 17.4$ years old. According to the method described above, 534 cases were classified into the following: type I consisted of 188 cases (35.2\%), type II consisted of 55 cases (10.2\%), type III consisted of 92 cases (17.2\%) and type IV consisted of 199 (37.2\%). When comparing these types, stones in Type I were significantly smaller than other groups. There was a significant difference in the surgical method depending on the location of stones. Different complications such as swelling, bleeding, tongue discomfort, ranula, recurrence, etc. have been reported and, together, they statistically show meaningful differences in the distribution depending on types. Conclusion The position of stone in Wharton's duct is important factor that can determine the method of surgical procedure or postoperative prognosis. We recommend 4 types classification of sialolithiasis and it can provide more specific diagnosis of disease and facilitate approach for treatment. Korean J Otorhinolaryngol-Head Neck Surg 2019;62(8):457-61

Key Words Complications · Salivary ducts $\cdot$ Sialolithiasis $\cdot$ Submandibular gland.

\section{서 론}

타석증(sialolithiasis)은 인구의 $1.2 \%$ 에서 발생하고 주 타 액선에 발생하는 가장 흔한 질환으로, 악하선에서 80 90\%, 이하선에서 5 20\%의 비율로 발생한다. 특히 악하선의 타석 은 원위부에서 $37 \%$, 근위부/문(hilum)에서 $53 \%$, 실질 내에

This is an Open Access article distributed under the terms of the Creative Commons Attribution Non-Commercial License (https://creativecommons.org/licenses/by-nc/4.0) which permits unrestricted non-commercial use, distribution, and reproduction in any medium, provided the original work is properly cited.
서 $10 \%$ 가 발생하는 것으로 보고되고 있다. ${ }^{1)}$

타석증은 식후 통증 및 부종, 반복적인 이차 감염을 통하 여 타액관 협착 및 타액선 실질 위축을 일으키며, ${ }^{2)}$ 보존적 치료의 효과가 낮거나 재발할 경우 타석의 제거가 필요하다. 단순 촬영술, 초음파, 전산화단층촬영, 타액선 조영술, 자기 공명영상 등을 통해 타석증을 진단하고, ${ }^{3-5)}$ 일반적으로 침샘 관 원위부에 위치하는 타석은 경구강 제거술(intraoral stone removal)로, 근위부일 경우 그 위치가 깊으며, 만성 감염과 구조적 변화가 동반되어 있는 경우가 많아 경부 절개를 통한 
악하선 절제술(submandibular gland resection)이 시행된다.

최적의 치료 방법 선정에 있어 술 전 타석의 위치, 크기 및 개수 등에 대한 고려가 필수적이며,' 국내외의 선행 연구에 서 다양한 타석증의 치료 방법, 예후, 술 후 합병증에 대한 연구가 진행되었으나, ${ }^{6-8)}$ 타석의 위치를 명확한 기준에 따라 분류하고 이를 치료 방법 선택에 활용한 연구는 드문 실정이 다. 이에 본 연구에서는 악하선 타액선관 내 타석의 위치를 기준으로 타석증을 분류하고, 분류 기준에 따른 예후를 분석 하여 타석 제거에 있어 적합한 치료 방법을 제언하고자 한다.

\section{대상 및 방법}

본 연구는 본원에서 2006년부터 2017년까지 양수 검사(bimanual palpation), 전산화단층촬영(computed tomography, $\mathrm{CT})$ 을 통해 악하선 타액선관 내의 타석증으로 진단받은 환 자 536명을 대상으로 후향적으로 의무기록을 검토하였다. CT 에서 타석이 확인되지 않는 경우 연구에서 제외하였으며 CT 영상을 토대로 타석의 위치와 크기를 분석하였고, 각 그룹 간의 타석의 위치, 치료 결과 및 합병증을 비교 분석하였다.

본 연구에서는 CT 영상의 축상면(axial view)에서 보이는 타석의 상대적인 위치를 비율을 통해 비교하였는데, CT에서 확인되는 악하선 타액선관 입구부(orifice)로부터 악하선 문 (hilum)까지의 길이(A)에 대한 입구부에서부터 타석의 중심 부까지의 길이(B) 간의 비를 산정하여 그 크기에 따라 type I (0 0.25), type $\operatorname{II}(0.25 \sim 0.5)$, type $\operatorname{III}(0.5 \sim 0.75)$, type IV $(0.75 \sim 1)$ 로 분류하였다. 타석의 크기는 타석의 최장경을 측정 하였으며 여러 개의 타석이 있는 경우에는 각각을 다른 case 로 연구에 포함하였다(Fig. 1).
본 연구에서 타석의 제거 방법으로 경구강 타석 제거술(intraoral stone removal, IOSR) 혹은 악하선 절제술(submandibular gland resection)을 시행하였고 타석의 위치가 원위부에 있는 경우 국소마취, 타석이 근위부에 있는 경우, 환자의 요청 혹은 악하선 절제술을 통한 제거 시 전신마취 하에 진행되었다. 수술 날짜 기준으로 1 주일 후에 외래에서 추적 관찰을 하였으며 의사의 소견과 환자의 증상을 종합하 여 합병증 여부를 평가하였다. 또한 수술을 시행했던 환자가 연구 기간 내에 수술 후 합병증으로 여겨지는 증상을 주소 로 병원에 다시 내원한 경우에도 합병증이 발생한 것으로 보 고하였다.

분류된 타석의 그룹에 따른 환자의 성별, 나이, 크기, 수술 방법, 재원 기간, 수술 시간, 수술 후 합병증과의 관련 요인에 대해 비교 및 분석하였고, 이에 대한 통계적 유의성을 확인하 기 위해 chi-square test, Fisher's exact test, analysis of variance를 사용하였고 $p$-value 0.05 미만을 통계적 유의성 이 있다고 판정하였다. 이번 연구는 본 기관의 임상연구심의 위원회(IRB)의 연구승인(승인번호: 2019-01-006-001)을 받 았다.

\section{결 과}

연구는 2006년 2월부터 2017년 5월까지 본원 이비인후과 외래, 응급실 혹은 타과 입원 후 협의 진료 후 악하선 타액선 관 내 타석증으로 진단되어 타석 제거술을 받은 536명을 대 상으로 하였다. 이 중 영상 정보가 존재했던 환자는 472명이 었고 총 타석의 수는 534개로 확인되었다. 다중의 타석증을 보였던 환자 중 23 명은 2 개의 타석을, 4 명의 환자는 3 개의 타
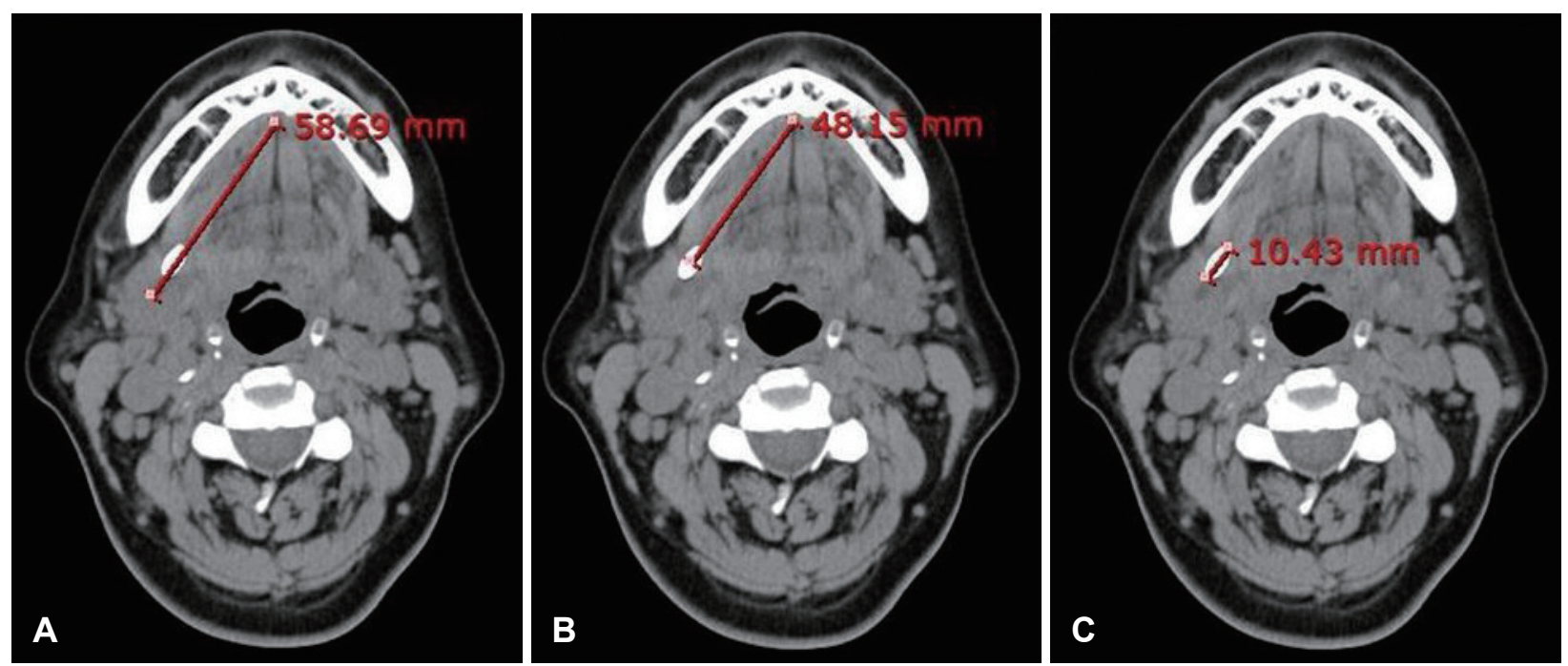

Fig. 1. Distance measurement method and classification. orifice to hilum $(58.7 \mathrm{~mm})(\mathrm{A})$, orifice to stone $(48.2 \mathrm{~mm})(B)$, diameters of stone $(10.4 \mathrm{~mm})(\mathrm{C}), 48.15 / 58.69=0.8$ (type IV) (B/A). 
석을 포함하였고, 1 명의 환자는 4 개의 타석에 대해 수술받았 다. 타석의 성별 분포는 남자 300건(56.2\%), 여자 234건(43.8\%) 이었고 이환율은 남자 환자가 여자 환자에 비해 1.28 배 높았 다. 연령은 8세에서 89세의 분포를 보였으며, 평균연령土표준 편차(standard deviation, SD)는 36.1 \pm 17.4 세였고, 타석의

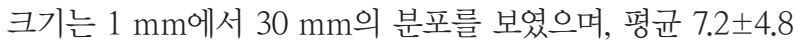
$\mathrm{mm}$ 였다. 타석의 발생은 우측 255예(47.8\%), 좌측 279예 $(52.2 \%)$ 발생하여 좌측에서 1.09 배 더 발생률이 높았다.

타석은 위에서 기술한 방법에 따라 type I 188예(35.2\%), type II 55예(10.2\%), type III 92예(17.2\%), type IV 199예 (37.2\%)로 분류되었다.

타석의 제거 방법은 국소마취하 IOSR을 시행한 경우가 206건(38.6\%), 전신마취하 IOSR을 시행한 경우가 157건 (29.4\%), 악하선 절제술을 시행한 경우가 171건(32.0\%)이었다 (Table 1).

술 후 합병증으로는 부종, 출혈, 혀 불편감 및 저린감, 안면 마비, 재발, 하마종, 구강 건조증, 심한 흥터 발생 등이 있었 고 술 후 합병증이 발생한 경우는 96예(18.0\%)였다(Table 2).

타석의 위치(type)에 특성의 차이를 살펴보면, 성별과 좌/ 우 방향, 나이는 통계적으로 유의한 차이를 보이지 않았다. 치료 방법은 type I 에서 국소마취하 경구강 제거술을 시행한 경우가 157 건(83.5\%)로 대부분을 차지하였고 type II, III에

Table 1. Demographics of patients who had undergone operation for sialolithiasis

\begin{tabular}{lc}
\hline \multicolumn{1}{c}{ Characteristics } & $\mathrm{n}(\%)$ \\
\hline Number of patient & 472 \\
Number of caculi & 534 \\
Age (years), mean \pm SD & $36.1 \pm 17.4$ \\
Sex, $\mathrm{n}(\%)$ & \\
$\quad$ Male & $300(56.2)$ \\
Female & $234(43.8)$ \\
Side, $\mathrm{n}(\%)$ & \\
Right & $255(47.8)$ \\
Left & $279(52.2)$ \\
Size (mm), mean \pm SD & $7.2 \pm 4.8$ \\
Site, $\mathrm{n}(\%)$ & \\
Type I & $188(35.2)$ \\
Type II & $55(10.2)$ \\
Type III & $92(17.2)$ \\
Type IV & $199(37.2)$ \\
Treatment, $\mathrm{n}(\%)$ & \\
L/A IOSR & $206(38.6)$ \\
G/A IOSR & $157(29.4)$ \\
G/A SMG resection & $171(32.0)$ \\
\hline
\end{tabular}

SD: standard deviation, L/A: local anesthesia, G/A: general anesthesia, IOSR: intraoral stone removal, SMG: submandibular gland
서는 국소마취 수술의 빈도가 줄고 전신마취하 경구강 제거 술을 시행한 경우가 많았다. Type IV에서는 악하선 절제술 을 시행한 경우가 128 건(64.3\%)로 가장 많았으며 분포의 차 이는 통계적으로 유의함을 보였다 $(p<0.001)$.

타석의 크기는 type I에서 평균 $(\mathrm{mm}) 5.4 \pm 3.6$, type II에서

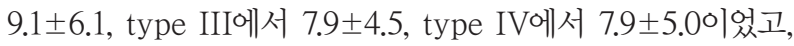
type I으로 분류된 그룹 내에서 타 그룹 내 타석의 크기보다 크기가 작았으며 통계적으로 유의하였다 $(p<0.001)$. 수술 후 합병증은 type I $11.2 \%$, type II $12.7 \%$, type III $29.3 \%$, type IV $20.6 \%$ 를 보여 type III, type IV에서 더 높게 나타났으며 이러한 분포는 통계적으로 유의한 차이를 보였다 $(p=0.001)$ (Table 3).

추가로 type I에서 IV로 갈수록 재원기간과 수술 시간이 길어짐을 확인할 수 있었으며 악하선 절제술 그룹에서 큰 차 이로 타 그룹에 비해 재원 기간과 수술 시간이 긴 것으로 나 타났다(Table 4).

\section{고 찰}

타석의 위치는 치료 방법을 결정하고 예후를 예측하는 데 에 있어서 매우 중요한 요소이다 그동안 국내외 여러 선행 연 구에서 타석증에 대한 역학과 수술 방법에 따른 예후를 분 석하였고, ${ }^{1,6-8)}$ Lustmann 등'의 연구에서 타석을 크기 별로 나누어서 그룹화한 예가 있었지만, 타석의 위치를 명확한 수 치에 따라 분류한 연구는 드물다고 볼 수 있다. 본 연구에서 는 500 개 이상의 타석들의 위치를 측정하여 분류하였고 그 에 대한 임상적 의미를 알아보고자 하였다.

먼저 연구 대상군의 역학적 특성을 살펴보면, 타석의 남녀 성비, 좌우 빈도는 이전의 연구들과 마찬가지로 차이를 보이 지 않았다. 평균 발생 연령은 36.1( \pm 17.4$)$ 세로 다른 연구에서 평균 40 50세에 발생했던 것에 비해서 현저히 낮은 수치를

Table 2. Complications after operation for sialolithiasis

\begin{tabular}{lc}
\hline \multicolumn{1}{c}{ Complications } & $\mathrm{n}=534$ \\
\hline Swelling & $24(4.5)$ \\
Tongue discomfort & $28(5.2)$ \\
Numbness & $11(2.1)$ \\
Ranula & $6(1.1)$ \\
Recurrence & $12(2.2)$ \\
Marginal weakness & $7(1.3)$ \\
Bleeding & $4(0.7)$ \\
Dry mouth & $2(0.4)$ \\
Scar & $2(0.4)$ \\
\hline Total & $96(18.0)$
\end{tabular}

Variables are presented as number (percentage). 438 (82.0\%) patients have no complications 
Table 3. Clinical features according to location of stones by location (type I-IV)

\begin{tabular}{|c|c|c|c|c|c|}
\hline & Type I & Type II & Type III & Type IV & $p$-value \\
\hline Age (years), mean $\pm S D$ & $34.6 \pm 17.6$ & $38.1 \pm 19.2$ & $34.8 \pm 16.2$ & $36.1 \pm 17.4$ & 0.223 \\
\hline Sex, n (\%) & & & & & 0.240 \\
\hline Male & $98(52.1)$ & $29(52.7)$ & $50(54.3)$ & $123(61.8)$ & \\
\hline Female & $90(47.9)$ & $26(47.3)$ & $42(45.7)$ & $76(38.2)$ & \\
\hline Side, n (\%) & & & & & 0.147 \\
\hline Right & $79(42.0)$ & $32(58.2)$ & $44(47.8)$ & $100(50.3)$ & \\
\hline Left & $109(58.0)$ & $23(41.8)$ & $48(52.2)$ & $99(49.7)$ & \\
\hline Size $(m m)$, mean \pm SD & $5.4 \pm 3.6$ & $9.1 \pm 6.1$ & $7.9 \pm 4.5$ & $7.9 \pm 5.0$ & $<0.001^{*}$ \\
\hline Treatment, n (\%) & & & & & $<0.001$ \\
\hline L/A IOSR & $157(83.5)$ & $31(56.4)$ & $11(12.0)$ & $7(3.5)$ & \\
\hline G/A IOSR & $26(13.8)$ & $20(36.4)$ & $47(51.1)$ & $64(32.2)$ & \\
\hline G/A SMG resection & $5(2.7)$ & $4(7.3)$ & $34(37.0)$ & $128(64.3)$ & \\
\hline Complications, n (\%) & & & & & 0.001 \\
\hline No & $167(88.8)$ & $48(87.3)$ & $65(70.7)$ & $158(79.4)$ & \\
\hline Yes & $21(11.2)$ & $7(12.7)$ & $27(29.3)$ & $41(20.6)$ & \\
\hline
\end{tabular}

*post-hoc tests (II, III, IV >I). SD: standard deviation, L/A: local anesthesia, G/A: general anesthesia, IOSR: intraoral stone removal, SMG: submandibular gland

Table 4. Analysis of length of hospital stay and operative time

\begin{tabular}{lcc}
\hline & $\begin{array}{c}\text { Length of stay } \\
\text { (day) }\end{array}$ & $\begin{array}{c}\text { Operative time } \\
\text { (min) }\end{array}$ \\
\hline All patients & 2.6 & 50.3 \\
Site & 1.4 & 34.3 \\
$\quad$ Type I & 2.0 & 43.7 \\
Type II & 2.8 & 50.5 \\
Type III & 3.9 & 65.8 \\
Type IV & & \\
Treatment & 0.7 & 28.7 \\
L/A IOSR & 2.1 & 40.9 \\
G/A IOSR & 4.2 & 70.7 \\
G/A SMG resection & & \\
\hline
\end{tabular}

G/A: genereal anesthesia, IOSR: intraoral stone removal, SMG: submandibular gland, L/A: local anesthesia

보였다.,8)

Sigismund 등이 시행한 연구에서는 평균 $8.3 \mathrm{~mm}$ 의 직경 을 보였고, Iro 등 ${ }^{8}$ 의 연구에서는 $7.2 \mathrm{~mm}$ 의 수치를 보여, 본원 의 평균 $7.2 \mathrm{~mm}$ 수치보다 크거나 비슷한 값을 보였는데, 이는 인종이나 신체 조건의 차이에 의한 것으로 생각된다. Shashinder 등 ${ }^{10)}$ 은 근위부에 발생한 타석증인 경우에 타석의 크기 가 유의하게 증가했다고 언급하였으나, 본 연구에서는 type II 타석의 평균 크기가 가장 큰 것으로 나타났으며 원위부에서 발생한 타석이 유의하게 작은 결과를 보여 기존의 연구와 차 이점이 있었다.

수술 방법은 type에 따라 유의하게 차이가 있는 것으로 나 타났는데, 이는 통상적으로 원위부 타석은 경구강 제거술, 근위부와 문, 실질 내 타석은 타액선 절제술을 시행하는 경 향과 일치한다고 볼 수 있다. ${ }^{6}$
Juul과 Wagner ${ }^{11)}$ 의 연구에서는 수술을 시행했던 환자 중 91\%에서 수술 후 특이 증상을 호소하지 않았으며 9\%에서 혀 감각 이상, 불편감 등을 호소하였다. Woo 등 ${ }^{12}$ 의 연구에서도 $83.3 \%$ 에서, Zhang 등 $^{13}$ 의 연구에서는 $85.6 \%$ 에서 술 후 합병 증을 보이지 않은 것으로 나타났다. 이는 본 연구에서 수술을 시행했던 534건 중 438건(82\%)에서 수술 후 특별한 합병증을 보이지 않은 것과 수치 상으로 유사한 결과로 볼 수 있었다. 발 생한 합병증으로는 혀 불편감(29.1\%), 부종(25\%), 재발(12.5\%), 감각 저하 $(11 \%)$ 등이 있었다. Type에 따른 합병증의 발생 빈 도는 유의한 차이를 보였으며 이에 기반하여, type III, type IV에 해당하는 환자군은 수술 후 관리에 더 주의를 기울여야 할 것으로 보이며, 또한 type 분류를 수술 후 예후를 예측하 는 지표로 사용할 수 있을 것으로 보인다. 또한 type I에서 IV 로 갈수록 재원 기간과 수술 시간이 늘어나는 것을 확인할 수 있었는데, 이는 각 type에 따른 수술 방법이 유의한 차이 가 보여 발생한 것으로 여겨진다. 이러한 결과를 볼 때, 타석 증 환자를 type에 따라 분류함으로써 치료 중 발생하게 될 의료 비용 및 치료 기간도 미리 예측하는 것이 가능할 것으 로 보인다.

본 연구의 제한점으로는 후향적 데이터 분석으로 이루어 진 연구 방식과 수술 이후 환자들이 대부분 1 2주의 짧은 추적 기간을 가졌기 때문에 장기간의 합병증에 대한 파악이 어려웠다는 것을 들 수 있다. 또한 치료 방법에 있어서 경구 강 타석 제거술 및 타액선 제거술만이 시행되었고 술자의 선 호에 따라 수술 방법이 결정되었다는 점과 수술 전 타석의 위 치와 크기를 인지한 상태에서 수술 방법을 결정했기 때문에 일종의 선택 편견(selection bias)이 발생한 점이 연구의 결과 
를 해석할 때의 제한점이 되었다.

타석증(sialolithiasis)을 치료함에 있어서 수술 전 영상 검 사를 통한 타석의 평가는 매우 중요하다. 특히, 타석이 발생 하는 위치는 치료 방법과 예후를 결정하는데 중요한 요소가 될 수 있다. 저자들은 본 연구에서 제시한 새로운 분류를 통 해 질환에 대한 진단을 세분화하고 이를 치료 및 연구에 사 용하는 것을 제안하는 바이다. 추후에는 전향적인 연구 방식 으로, 더 큰 모집단에 대해 각 type별 수술 방법에 따른 결과 의 차이를 살펴보는 연구가 시행되어야 할 것이다.

\section{ORCID}

Bumjung Park

https://orcid.org/0000-0001-6074-6339

\section{REFERENCES}

1) Sigismund PE, Zenk J, Koch M, Schapher M, Rudes M, Iro H. Nearly 3,000 salivary stones: Some clinical and epidemiologic aspects. Laryngoscope 2015;125(8):1879-82.

2) Choi YC, Shim JH, Kang JJ, Choi HS. Case report: Parotid sialolithiasis. Korean J Otorhinolaryngol-Head Neck Surg 2007; 50(9):829-32.

3) Rzymska-Grala I, Stopa Z, Grala B, Gołebiowski M, Wanyura H, Zuchowska A, et al. Salivary gland calculi - contemporary methods of imaging. Pol J Radiol 2010;75(3):25-37.

4) Schwarz D, Kabbasch C, Scheer M, Mikolajczak S, Beutner D, Luers JC. Comparative analysis of sialendoscopy, sonography, and CBCT in the detection of sialolithiasis. Laryngoscope 2015;125(5):
1098-101.

5) Vogl TJ, Al-Nawas B, Beutner D, Geisthoff U, Gutinas-Lichius O, Naujoks C, et al. Updated S2K AWMF guideline for the diagnosis and follow-up of obstructive sialadenitis--relevance for radiologic imaging. Rofo 2014;186(9):843-6.

6) Eun YG, Chung DH, Kwon KH. Advantages of intraoral removal over submandibular gland resection for proximal submandibular stones: A prospective randomized study. Laryngoscope 2010;120 (11):2189-92.

7) Witt RL, Iro H, Koch M, McGurk M, Nahlieli O, Zenk J. Minimally invasive options for salivary calculi. Laryngoscope 2012;122(6): 1306-11.

8) Iro H, Zenk J, Escudier MP, Nahlieli O, Capaccio P, Katz P, et al. Outcome of minimally invasive management of salivary calculi in 4,691 patients. Laryngoscope 2009;119(2):263-8.

9) Lustmann J, Regev E, Melamed Y. Sialolithiasis. A survey on 245 patients and a review of the literature. Int J Oral Maxillofac Surg 1990;19(3):135-8.

10) Shashinder S, Morton RP, Ahmad Z. Outcome and relative cost of transoral removal of submandibular calculi. J Laryngol Otol 2011; 125(4):386-9.

11) Juul ML, Wagner N. Objective and subjective outcome in 42 patients after treatment of sialolithiasis by transoral incision of Warthon's duct: A retrospective middle-term follow-up study. Eur Arch Otorhinolaryngol 2014;271(11):3059-66.

12) Woo SH, Jang JY, Park GY, Jeong HS. Long-term outcomes of intraoral submandibular stone removal in children as compared with adults. Laryngoscope 2009;119(1):116-20.

13) Zhang L, Escudier M, Brown J, Capaccio P, Pignataro L, McGurk M. Long-term outcome after intraoral removal of large submandibular gland calculi. Laryngoscope 2010;120(5):964-6. 